INTERNATIONAL CONFERENCE ON ENGINEERING AND PRODUCT DESIGN EDUCATION

9-10 SEPTEMBER 2021, VIA DESIGN, VIA UNIVERSITY COLLEGE, HERNING, DENMARK

\section{TEACHING PRODUCT DESIGN THROUGH AN ONLINE ILLUSTRATED INTERFACE}

Richard Elaver

${ }^{1}$ Appalachian State University

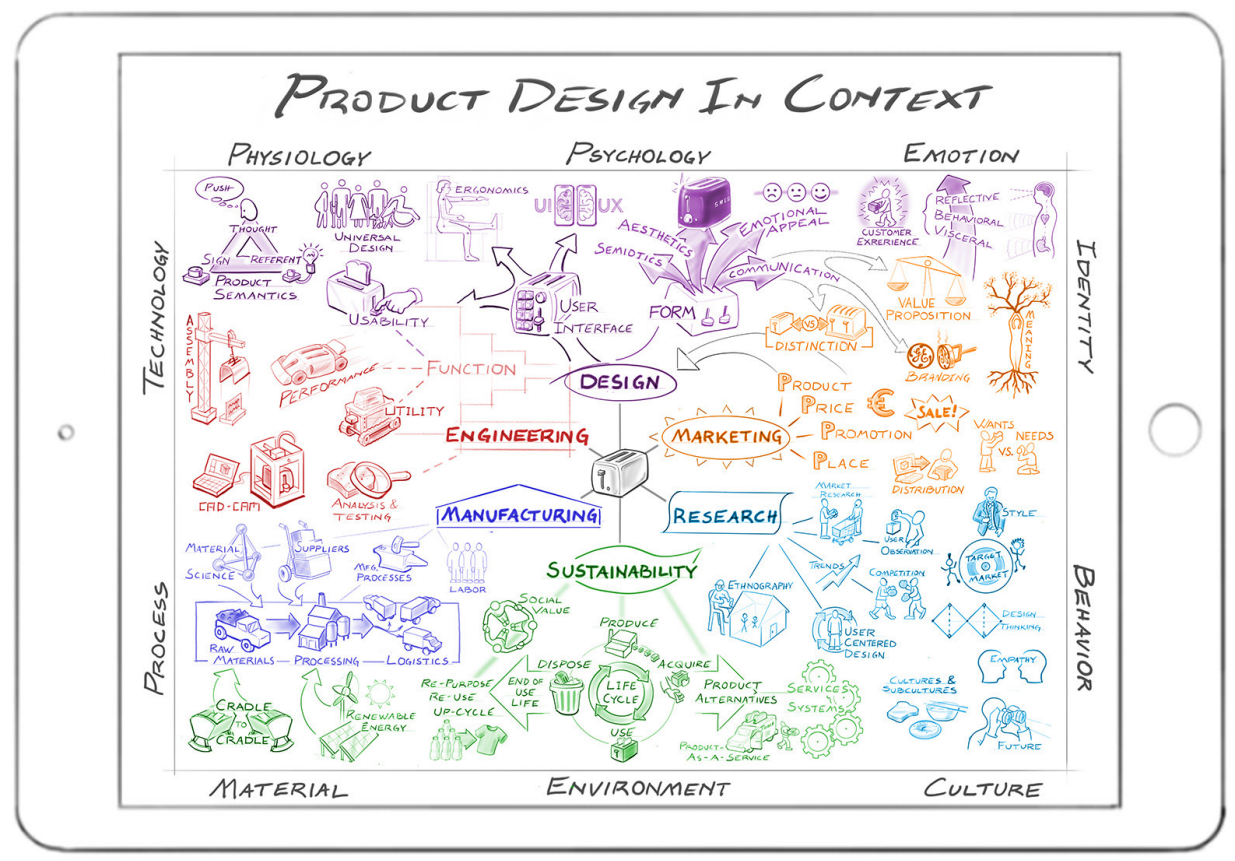

Figure 1. Visualization of online/digital interface for 'textbook'

\section{Introduction}

Designers tend to communicate through sketches. Yet our online teaching environments are typically linear structures, based on databases, with limited visual expression. Is it possible to have an online 'textbook' for Product Design that is illustrative in style, non-linear in organization, intuitive, and visually compelling?

At E\&PDE 2020, I presented a visual paper culminating in a single graphic that attempted to depict the whole of the Product Design field, and all considerations that go into designing a product [1]. This was based on an Introduction to Product Design course I developed and taught for the past ten years. In 2020, that course shifted to an online class, and like so many instructors had to do in a rush, the content from the live class was simply redirected to an online environment. It has become clear that there are better strategies for teaching online, rooted in the digital environment, and the fluidity and flexibility it provides.

Based on feedback from colleagues in the 2020 E\&PDE conference, the goal for this paper is to visualize how the illustration from the 2020 paper could become an interactive graphic interface for teaching product design. More specifically, the intention is to make the Product Design in Context graphic into the landing page for a new type of online course, in which each graphic icon becomes a dynamic link to the content related to that subject. In this model, the class content is more organically presented, as students navigate through interlinked content, always returning to the central graphic as the home page. Students will move at their own pace, and assessment will be competency-based through online quizzes in each subtopic.

To do this well and complete would be a multi-year project. The purpose of this visual paper is to explore the flow of that information through illustrations, as a simulation of the online experience. This is intended to be a first draft of one section of the class, covering one of the six Key Functions in the radial arrangement of the main graphic. This paper explores how to navigate the hierarchy of content, how to show interconnections to related content, and how to maintain the same illustrative visual language throughout the online experience. 


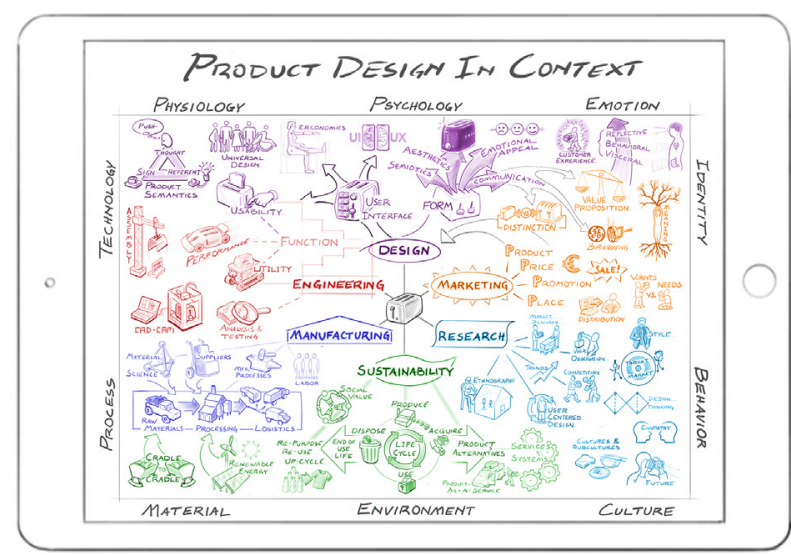

1) Landing Page

- Graphic Table of Contents

- From here, can click on any icon for more information

- Or, click center to start topic navigation

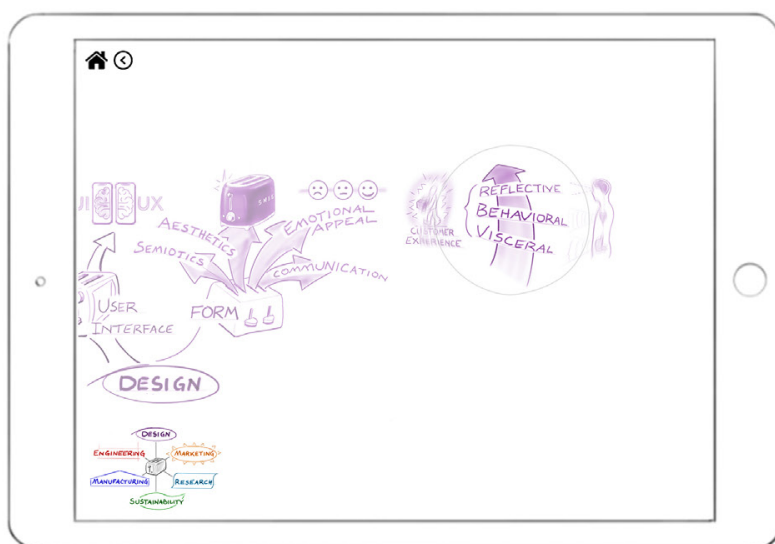

4) Sub-topic Selection

- Mouse-over animation magnifies icon

- Select icon for more information

- Major Topic navigation remains in lower left corner

E\&PDE2021/1233

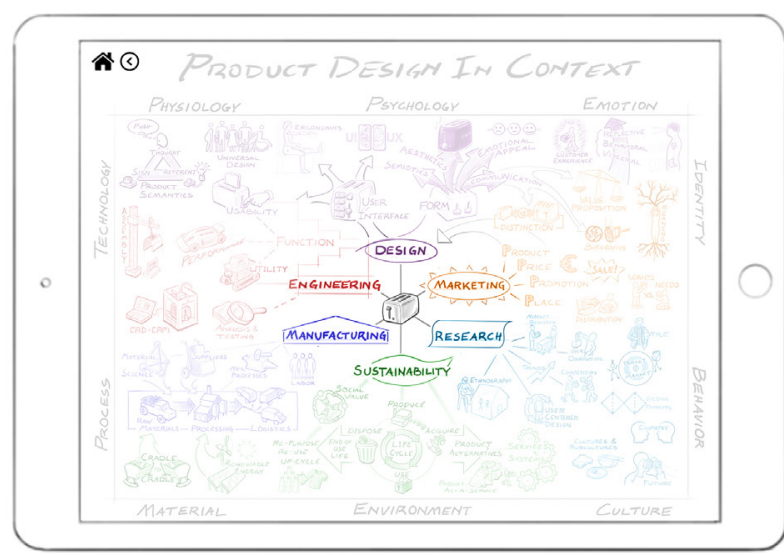

2) Topic Navigation

- Highlights 6 Major Topics at center

- Select one to isolate that topic and subtopics of same color

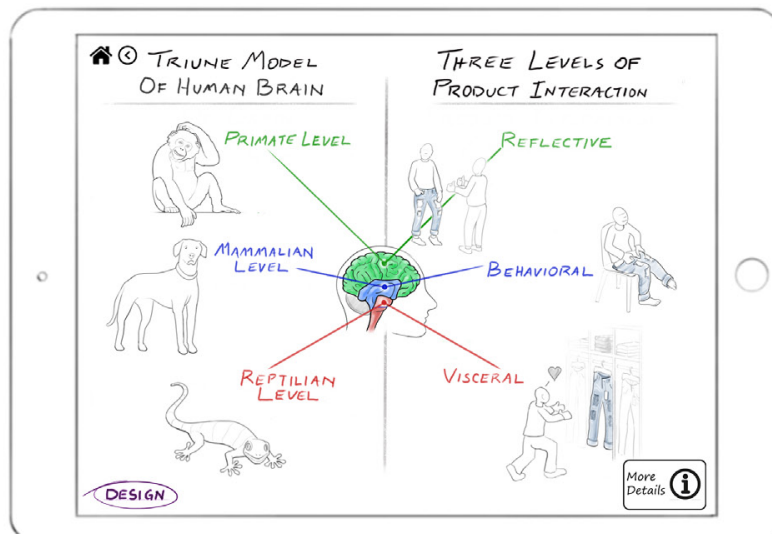

5) Expanded Graphic on Sub-topic

- Graphic depicting more info about subtopic

- Link to Major Topic remains in lower-left

- Link for detailed content in lower right

Figure 2. Proposed work-flow for online interface

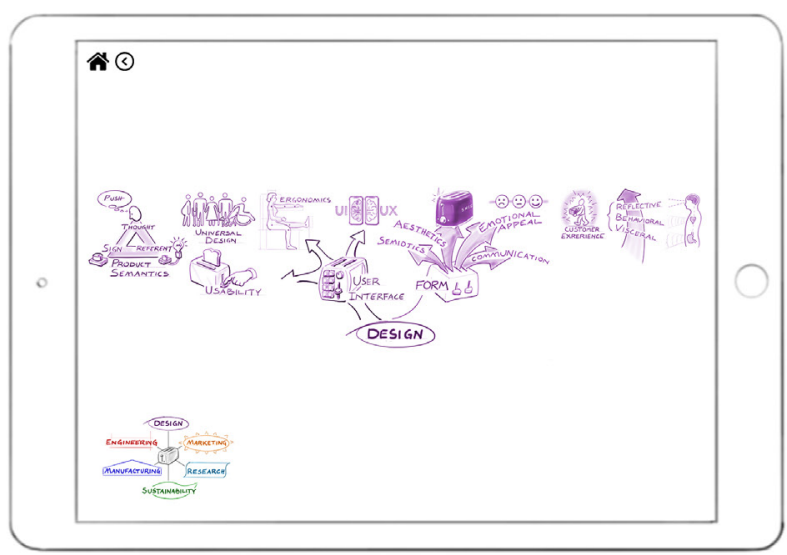

3) Major Topic Isolation

- Selected topic isolated and centered

- Can select sub-topics

- Major Topic navigation remains in lower left corner

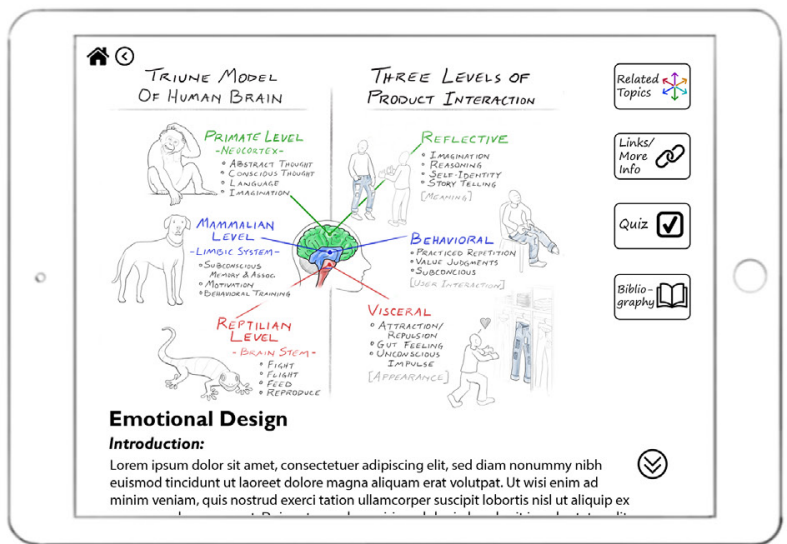

6) Detailed Content and Text

- This page mimics a printed textbook, with scroll-through of multiple pages of text

- Includes more detailed info-graphics

- Added info, quiz, and links on right side 


\section{Web Interface and Information Hierarchy}

The 2020 graphic, Product Design in Context is structured in a radial pattern, with six 'Key Functions of Product Development' at the center. In Figure 1, color has been added to that graphic (previously black \& white) to give each of those six areas a distinct identifying feature. This has been done to organize the hierarchy of the image and make it easier for the user to orient.

Figure 2 outlines a potential work-flow for the web-based interface of a kind of 'textbook' for teaching product design. It uses the Product Design in Context graphic as the main landing page, and as a visual Table-of-Contents (Step 1 in Figure 2).

The goal is to have each icon in the Table of Contents be a section of the text. So, each icon is a link to a multi-page write-up on that specific sub-topic, with additional infographics to expand on the sub-topic. In this model, it would be possible to link to any graphic directly from the home page. Alternatively, in order to work through the content in a more organized way, the user would first move the mouse over the center of the graphic to highlight the 6 Key Functions (Step 2 in Figure 2). These would be the six 'sections' or chapters of this online textbook. From there, the user would be able to click on any one of the six labels/icons to isolate that section of the Table of Contents (Step 3 in Figure 2). This is intended to clarify and simplify the user experience, so they have fewer sub-topics in scope from which to choose.

Next, the user would select a specific icon/sub-topic to delve into. (Step 4 in Figure 2). That icon would link to a more expanded graphic on the topic, visualizing a more in-depth depiction of the subject, and mapping out the detailed content for that section (Step 5 in Figure 2). This graphic could be used as a refresher or study-guide to review the topic, or the user can click a link for 'more detailed information' in order to get the full text (Step 6,

Figure 2). The full text would mimic a physical textbook, with a combination of infographics, photographs, and text.

At this level (Step 6 of Figure 2), the text on each topic will be approximately 1-3,000 words in length (or 2-6 printed pages). The reader would access the content by scrolling down, and continue to the end of the topic. There are 55 icons in the current Table of Contents graphic, so the total text length would be approximately $100 \mathrm{k}$ words, or 200 printed pages. E\&PDE2021/1233
It would be relatively simple to make this text accessible for differently abled users, because the interface from here is a standard infinite scroll. Alternatively, this text and infographics could be exported as a printed textbook.

The right side of the page for each sub-topic (Step 6 of Figure 2) is populated with additional links to access further information:

1. Related topics in the 'textbook'. This would provide a collection of links to other icons from the visual Table of Contents that are closely related to the current subject.

2. Links to additional materials: This would provide a collection of links to outside resources, online articles, and reference materials for anyone wanting to learn more on the current topic.

3. Link to a quiz. For students using the text for a class, this would be a place for an assessment of their understanding of the topic. Through such quizzes, students can move through the material in a self-paced manner until they pass the quiz for each section.

4. Link to bibliography and sources used for the current topic.

To maintain the visual nature of the interface, a handful of navigational tools have been integrated into this proposed interface. These are intended to keep the organizational hierarchy visible at all times and create a more intuitive flow of information.

1. All pages would have a 'home' and 'back button' on the top left. 'Home' would always return to the Product Design in Context main graphic, or Table of Contents.

2. When navigating any one of the 6 'Key Functions' (Steps $3 \& 4$ in Figure 2), the central wheel with all 6 would remain in the lower left corner. The user can click on any one of those icons to shift to another section.

3. While viewing any specific sub-topic (Steps 5-6 in Figure 2), the icon for the current section (e.g. Design) would replace the 6-part 'Key

Functions' links in the lower left corner, so the user could return to the overview of the current section at any time.

4. The graphic/icon from the table of contents for a subtopic would be visible on the information page for that subtopic, as a visual reminder of the link, making it easier to re-find the information at a later time. 


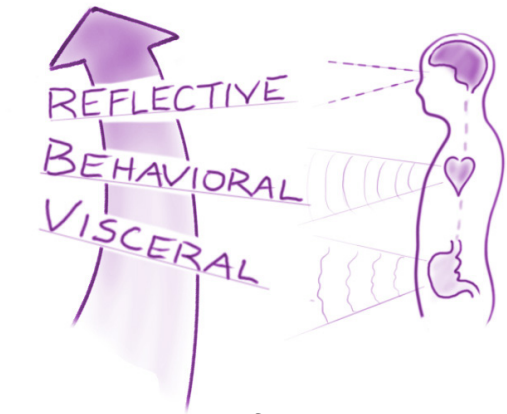

Figure 3. Icon from the home page that linked to the current sub-topic, Emotional Design

\section{Key Subtopics in Section 1, Design}

The following pages visualize the graphics that might be used to elaborate on key sub-topics in the Design section of the text. Design is one of the Six Key Functions of Product Development, or one of the six 'chapters', and the central subject for the proposed 'textbook'. The Design topic has 14 unique icons/sub-topics, while the other sections have 6-12. Similar to the Product Design in Context graphic, each of these infographics is intended to convey a great deal of information in an organized and intuitive way. The text below each graphic would be explanatory and use the graphic for reference. That text is not included in this document because it is too long to fit, and this 'visual paper' is intended to present the visual aspects of a possible online interface.

\subsection{Emotional Design}

This sub-topic outlines some key concepts from Donald Norman's book, Emotional Design. It also aligns Norman's 3-tiered interaction with MacLean's [2] Triune model of the human brain, giving physiological parallels for Norman's psychological concepts.

\section{Three LeVELS OF ProDUCT InTERACTION}

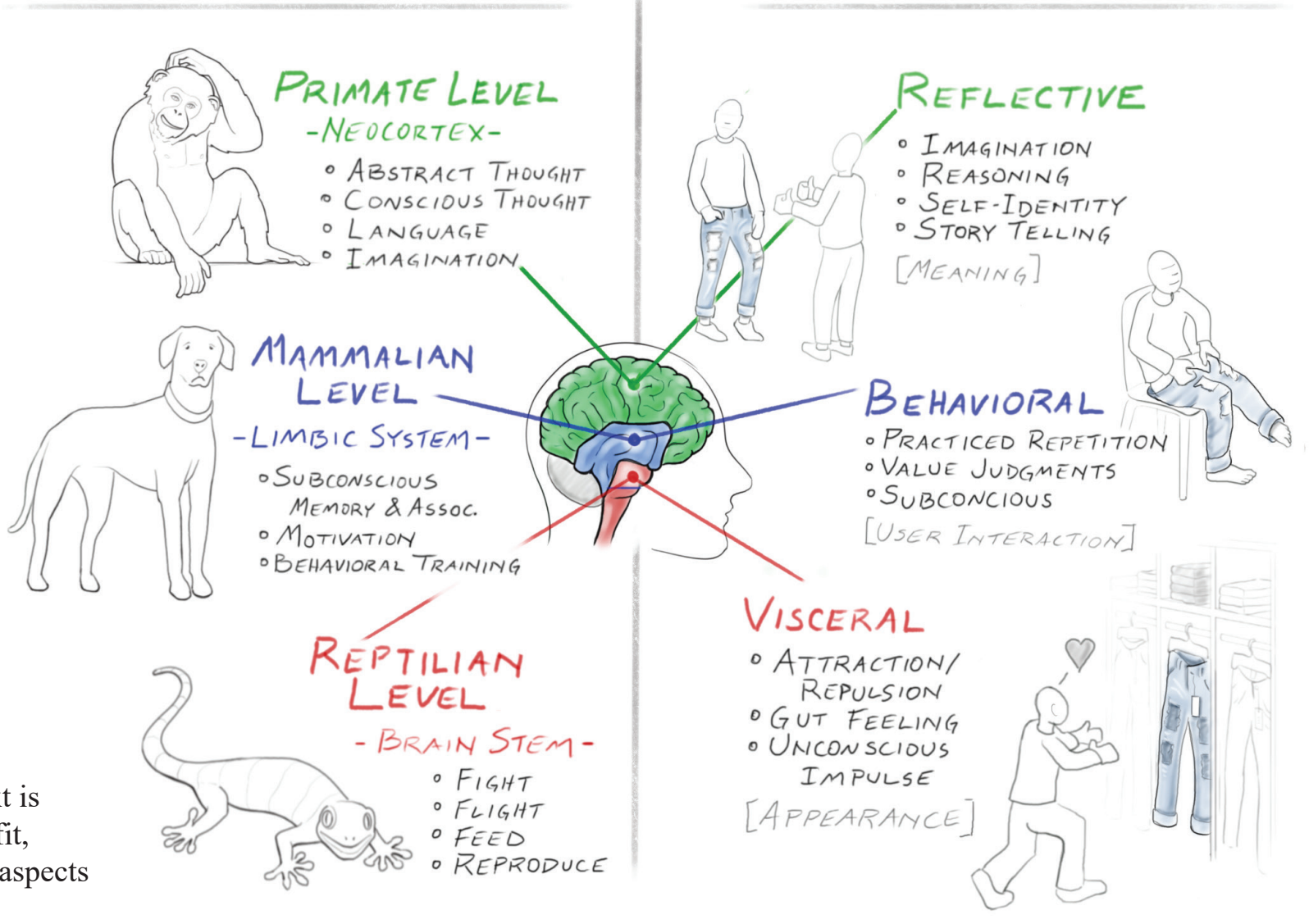

Figure 4. Graphic Outlining the key concepts from Donald Norman's Psychopathology of Design, aligned with MacLean'sTriune model of the brain 


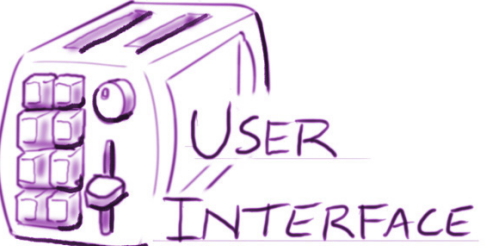

Figure 5. Icon from the home page that linked to the current sub-topic, User Interface

\subsection{User Interface}

This sub-topic outlines some of the key concepts from Donald Norman's book, The Design of Everyday Things. The structure organizes how users make sense of products by ascertaining the attributes through visibility, affordances, mapping and feedback, in order to develop a conceptual model of the product [3].

Users tend to do this subconsciously, and very quickly. And it can be difficult to slow down that perceptual process to witness 'how' we see and know things, noting observations that precede our already-established conceptual models. This graphic and section of the text is intended to break down a few simple product examples (e.g. a pair of garden shears) using the terms/concepts developed by Norman, in order to give readers practice in applying those terms and slowing down their own perception of the world around them.

A key learning outcome here is to develop a better understanding of the work that underlies intuitive design. Strangely, when design is done well, and a product is successful in its usability, it is because the necessary clues have been effectively communicated subconsciously, and the design work is undervalued because it isn't overtly apparent.

Figure 6. Graphics Outlining the key concepts from Donald Norman's Psychopathology of Design, aligned with MacLean'sTriune model of the brain
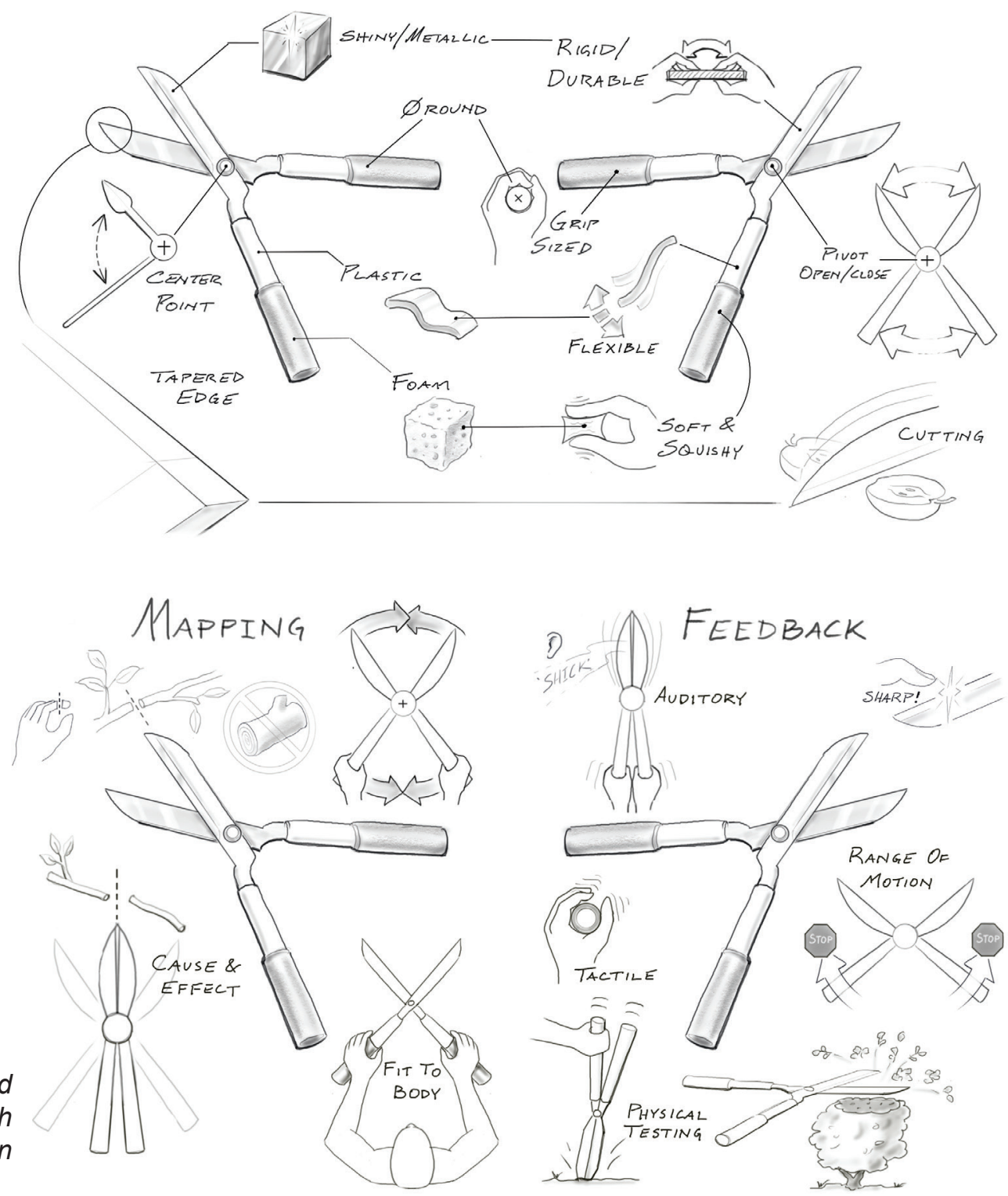


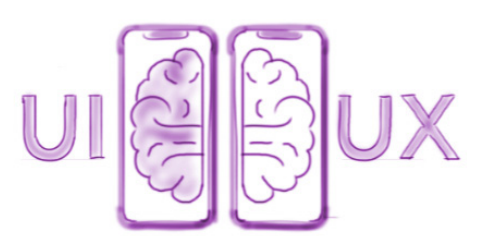

Figure 7. Icon from the home page that linked to the current sub-topic,

$$
\text { UI/UX }
$$

\subsection{UI/UX}

User Interface and User Experience Design are professions unto themselves. At the same time, they are central aspects of any product's design. This sub-topic will focus on the multi-sensory experience of how users interface with products, and how we engage with and understand products and their attributes.

The learning outcome is to gain a broader definition of UI as involving any point of interaction between the user and the product, not just buttons on flat screen. Similarly, UX design involves a diversity of product attributes that facilitate a specific kind of experience, and this goes well beyond the logic diagram of inputs and outputs.

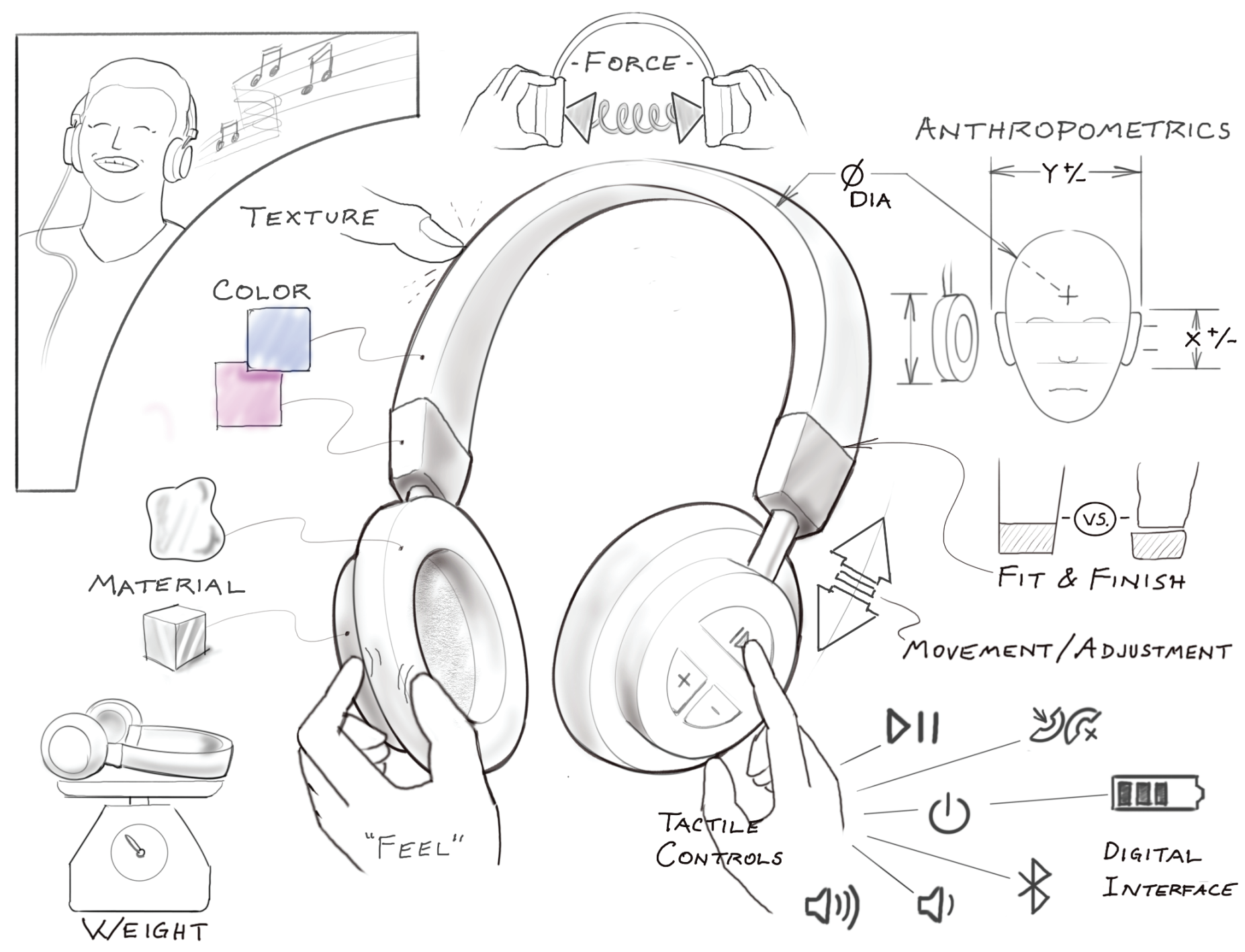

Figure 8. Graphic outlining the many different points of interface between a user and a product, and the different sensory perceptions used to understand the product 


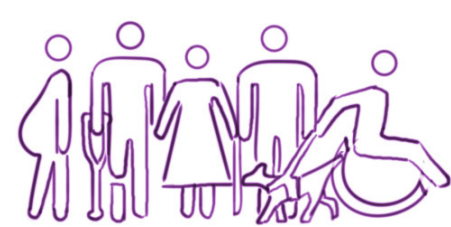

UNIVERSAL

DESIGN

Figure 9. Icon from the home page that linked to the current sub-topic,

Universal Design

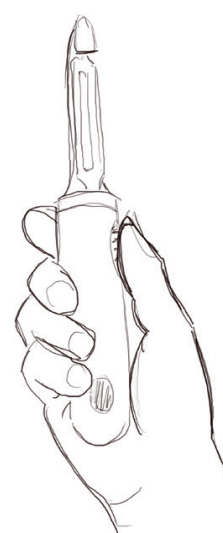

Figure 10. Drawing of Oxo Good-Grips

Peeler design by Smart Design

\subsection{Universal Design}

This sub-topic explores the subject of 'universal design' as an extension of User Interface Design. Universal Design has come to mean design that is usable by all people, regardless of ability, and might also be called inclusive design. The central concept is that a product that is useful for someone with atypical abilities, then it can be designed to be more useful for everyone. A classic Product Design example is the potato peeler designed by Smart Design for Oxo - the beginning of the 'Good Grips' product line (Figure 10). By redesigning the handle of the peeler to be more usable for people with arthritis, they designed a tool that was more usable by everyone.

In the past, designing for people of different abilities was more commonly focused on creating a specialty product for that subgroup, e.g. harness for guide dogs. However, low-volume production tends to mean a E\&PDE2021/1233 higher cost-per-unit, and this resulted in specialty products that were often cost-prohibitive and/or difficult to bring to market.

With Universal Design, the intention is to create products and experiences that are accessible to more people, while also benefiting from economies-of-scale in their production and distribution, making the product move readily available - a double-meaning for accessible.

The example depicted above (Figure 11) is for curb cuts (a.k.a. dropper kerbs in the UK), which were initially intended to aid people in wheelchairs [ref]. The innovation turned out to be useful for many different people, from cyclists to those in high-heeled shoes, so it became a 'universal design' more widely implemented. 


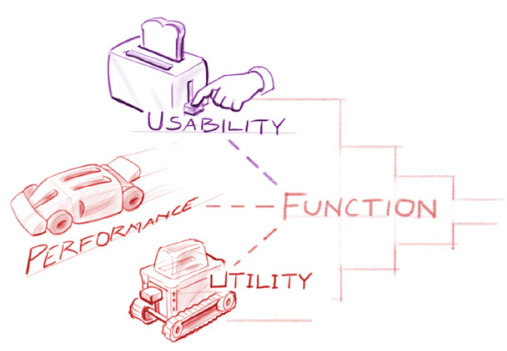

Figure 12. Icon from the home page that linked to the current sub-topic, Function

\subsection{Function}

Function, regarding products, is often thought of in a binary way: does it work, or doesn't it. From a design perspective, and considering user experience, 'function' has three main aspects: utility, usability, and performance.

This sub-topic explores those three areas, defining each, and giving examples of product variations that are more or less successful in each area, helping the reader differentiate the three aspects.

Here, a drill is used as an example: the brace drill as an example of pure utility; an electric drill, with a pistol grip, is a contrasting example of increased usabili-

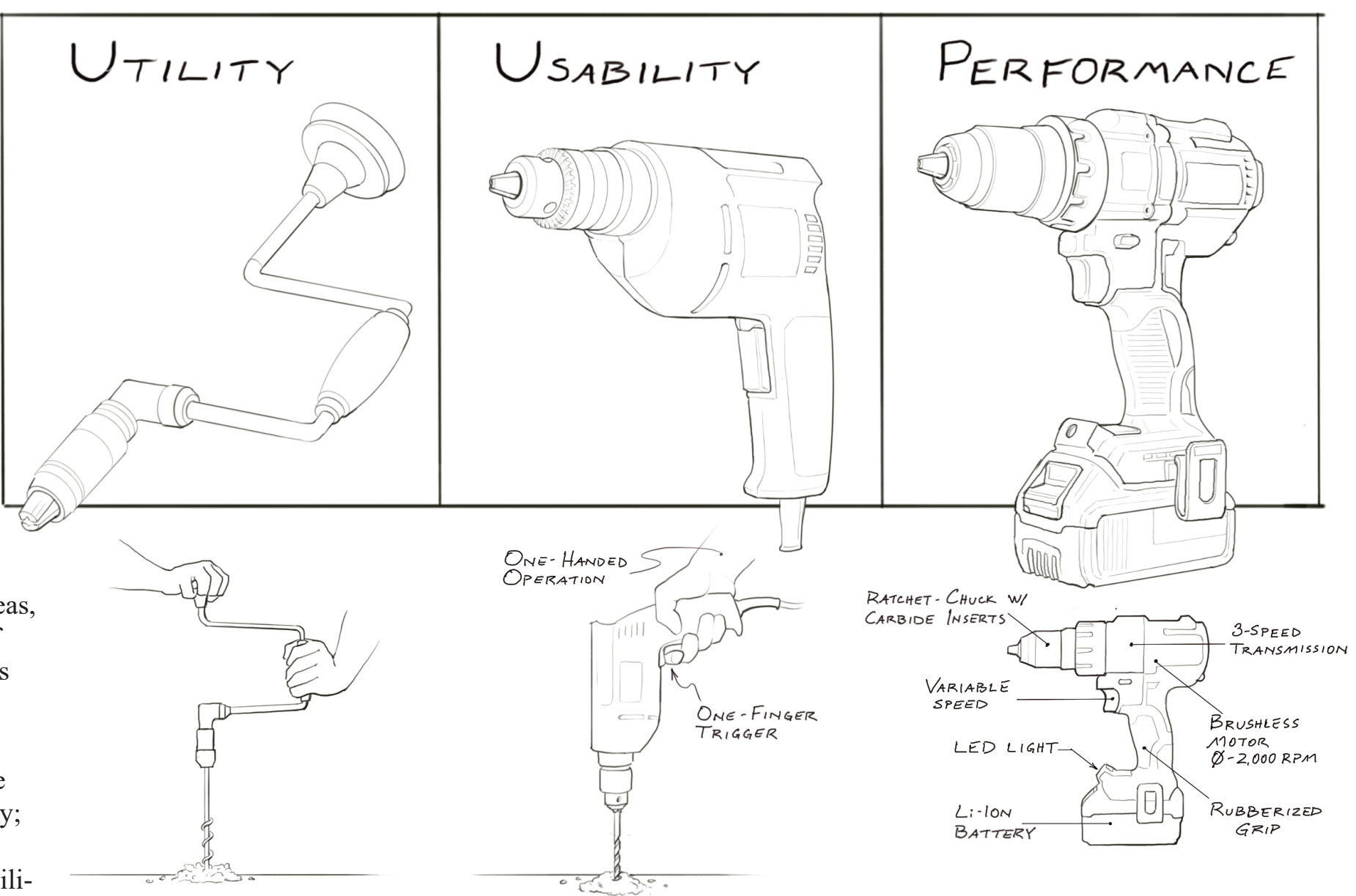

ty; and a high-power, high-tech cordless drill as an example of 'performance'.

This topic bridges the Design and Engineering section, and these aspects of function tend to be addressed by both professions, with product designers more focused on 'usability' and engineers more focused on 'utility'.

E\&PDE2021/1233
Figure 13. Graphic outlining the three different aspects of 'function': utility, usability, and performance 


\section{Outcomes}

- This paper has depicted a possible visual interface for an online version of the proposed 'textbook', using the Product Design in Context graphic as the home page and visual Table of Contents. This has not been finalized, but the visualization will help to convey the concept and solicit collaborators.

- Five of the info-graphics for the Design section/chapter have been illustrated, mapping out key concepts to be communicated in the text.

- A publisher has been contacted for this textbook proposal and has expressed interest in this idea. This paper will serve as an example of the kind of content that will be contained in the 'textbook', and how it will be shown online.

- The written text is a work-in-progress. It was through writing a draft of that text that key concepts emerged for the above info-graphics. The exchange between text and image will be essential for the further development of this 'textbook', as the writing helps determine what needs to be visualized, and the infographics help elaborate the writing.

- The colored version of the Product Design in Context graphic was reviewed with a group of 4th-year undergraduate Product Design students and received encouraging feedback. The students thought the home page infographic would be useful for current and future projects as a reference. By reviewing the Product Design in Context graphic, with a project in-mind, they were led to consider specific aspects of their project that were not previously considered. Their suggestion was to use this in more advanced classes for students, or young professionals, to think more broadly about projects, and to spurn them into specific areas and subtopics they may have forgotten about.

\section{Next Steps}

- Continue to work on text portion and assemble a complete sample 'chapter' with full text, infographics, supporting images/photos, and reference materials to share with publisher(s).

- Gather feedback from colleagues, both in academia and practicing professionals, on the concept and content.
- Develop more of the infographics and test them by using them in teaching in my future classes. This will provide opportunities for feedback on the efficacy of the infographics, and if they help students to better grasp the concepts.

- Seek collaborators to further the project. Specifically, web and/or interaction designer(s) to help explore the web interface and how that might appear and function. Also, potential collaborators in creating text and/or visual content. This project may be more likely to happen if it is generated by multiple authors.

\section{Conclusions}

The ultimate goal for this effort is to use the web-based interface of the proposed 'textbook' as a primary teaching tool for my Introduction to Product Design course, and to make it available to others teaching similar classes. Ideally, the text, images, and digital interface can be created in ways that are also appealing and useful to others in, or related to, the field of product design. This kind of visual introductory text could become a useful tool for practicing designers to share with potential clients in order to communicate what designers do and how they add value to a project. Similarly, it could be used by students and young professionals as a learning tool, with accessible reminders of more diverse considerations in a design project.

For now, this paper serves as a useful incremental step in visualizing the more complete 'textbook' concept. And it has already been useful in testing some of the infographics contained.

\section{References}

[1] Elaver, R. Product Design in Context. Visual Paper presented at E\&PDE, 2020, location??

[2] Komninos, A. The Concept of the Triune Brain, Interaction Design Foundation. Available: https://www.interaction-design.org/literature/article/ the-con cept-of-the-triune-brain [Accessed on 2021, 8 March]

[3] Norman, D. The Design of Everyday Things, 2013, (Basic Books, NY) 
